\title{
Men's Exposure to Women's Odors: The Effect of Women's Waist to Hip Ratio and Steroid Hormones
}

\author{
Ana Lilia Cerda-Molina ${ }^{1^{*}}$, Leonor Hernández-López ${ }^{1}$, Javier Iván Borráz-León ${ }^{1}$, Claudio De la O-Rodríguez ${ }^{1}$ and Roberto Chavira-Ramírez ${ }^{2}$ \\ ${ }^{1}$ Departament of Ethology, National Institute of Psychiatry, Mexico \\ ${ }^{2}$ Departament Reproductive Biology, National Institute of Medical Sciences and Nutrition, Mexico
}

"Corresponding author: Ana Lilia Cerda-Molina, Departament of Ethology, National Institute of Psychiatry, Mexico-Xochimilco 101, Col. San Lorenzo Huipulco, Tlalpan 14370. Mexico, Tel: 0155 41605109; Fax: 0155 56559980; E-mail: alcm@imp.edu.mx

Received date: June 06, 2014, Accepted date: July 31, 2014, Published date: August 07, 2014

Copyright: (c) 2014 Cerda-Molina AL et al. This is an open-access article distributed under the terms of the Creative Commons Attribution License, which permits unrestricted use, distribution, and reproduction in any medium, provided the original author and source are credited.

\begin{abstract}
Previous research has shown that axillar and vaginal odors from ovulating women are recognized by men, but no research has been done exploring whether body odors signal other physical attributes of women such as waist-tohip ratio (WHR) or endocrine status. Our goal was to investigate whether testosterone increased in men after smelling axillary odors of women with different WHR and with low or high levels of steroid hormones. We measured men's testosterone before and after $30 \mathrm{~min}$ of being exposed to fresh axillar odors collected from young women or a neutral odor as control situation. Men had to rate the attractiveness and intensity of the scent. We compared the response of men according to women's WHR and salivary testosterone, estradiol and progesterone. Although the main literature commonly reports that men judge a WHR around 0.7 to be more visually attractive, our results showed that men rated samples of high WHR (0.75-0.84) and high estradiol women as more attractive. In addition, men's testosterone increased after smelling the odors of high WHR, high estradiol and high testosterone women. High WHR women exhibited the highest testosterone and estradiol levels compared to the other WHR categories $(0.66-0.74)$. We concluded that scents are cues that not only signal fertility but also physical attributes related to reproductive health.
\end{abstract}

Keywords: Axillar odors; Waist-to-hip ratio; Testosterone; Estradiol

\section{Introduction}

In humans, there are many attractive physical and non-physical traits that might influence mate selection, e.g., facial symmetry [1], body shape [2], body fat [3], or body scent [4-6]. Most research has claimed that humans, similar to other mammals, produce scents that influence not only sexual attraction, but emotions, moods, behaviors, and endocrine function in both sexes [7]. In humans, odor production is primarily concentrated in the apocrine glands of the axillae and is a process linked to the presence of microorganisms (e.g., bacteria). Axillary glands develop around puberty, suggesting a dependence on reproductive hormone fluctuations [8]. Glandular secretions are composed of different fatty acids and steroids, which, in conjunction with the metabolism of bacteria, promote strong odors. Some authors have reported specific androgen-related steroids (i.e., 16-androstenes) as the main component of human axillary odors of both sexes [9]. In women, some of these components have been implicated in the modulation of LH secretion and menstrual synchronization [10].

Different studies have indicated that men can perceive feminine axillary odors as a potential cue to ovulation [6,11-14]. Gildersleeve et al. [6] demonstrated that men accurately discriminated between scent samples from women with high or low fertility and they rated high fertility samples as more attractive than the low fertility ones. In addition, Miller and Maner [13] found that men exposed to T-shirts used by ovulating woman displayed higher levels of testosterone (T) 15 minutes after the exposure, than men exposed to the scent of a nonovulating woman or to a control scent. However, there has been some recent debate about whether this can occur, because Roney and Simmons [15] did not support Miller and Maner's findings.

On the other hand, Rikowski and Grammer [4] proposed that humans use multiple signals to choose a partner in order to reduce the probability of error when assessing mate quality, suggesting the existence of some concordance of the information people perceive from others. For instance, Cornwell et al. [16] described that women prefer body odors collected from men with a high degree of body symmetry. Both, odors and symmetry are signals conveying individual reproductive information, indicating whether the individual is in good health condition [17], nevertheless the perception of those signals could be modulated by the environment and a learning process [1]. Another parameter signaling good reproductive health during human mate selection is the waist-to-hip ratio (WHR) of women, a measurement that compares the circumference of the waist to that of the hips [2]. According to Singh [18] in women of reproductive age, a gynoid body fat distribution is a reliable indicator of their sex hormone profile, greater success in pregnancy and less risk for major diseases [19-21]. As demonstrated by an extensive literature, men judge a WHR of around 0.7 to be the most appealing shape $[1,18,22,23]$. In addition, higher WHR $(>0.80)$ has been considered an index of upper body obesity and abdominal fat accumulation; therefore, women in this condition are more susceptible to major diseases such as diabetes, cardiovascular disorders and ovarian cancers than women with a WHR between 0.7 and 0.79 [2,20,24]. Singh [2,23] has indicated that the distribution of body fat, as measured by waist and hip circumference, rather than the overall body fat mass, is correlated with the onset of pubertal endocrinological activity and is a more accurate predictor of many diseases and sex hormones disturbances. Based on this information, we hypothesized that body 
Citation: Cerda-Molina AL, Hernández-López L, Borráz-León Jl, O-Rodríguez CDL, Chavira-Ramírez R (2014) Men's Exposure to Women's Odors: The Effect of Women's Waist to Hip Ratio and Steroid Hormones. J Steroids Horm Sci 5: 141. doi:

shape, measured by WHR could be related to the attractiveness of women odors. The existing literature about the reactions of men to feminine scents implies that masculine testosterone could be influenced by the changes of odors during the menstrual cycle $[13,14]$, although Roney and Simmons [15] claimed the contrary. In addition, it is possible that women differ in the degree of odor secretion according to their endocrine state or body fat distribution.

The purpose of this research was to determine whether testosterone levels change in men after smelling freshly collected axillary scents of women but analyzing the influence of the donor's hormonal concentrations and WHR, as we previously analyzed the cycle phase [14]. According to the aforementioned evidence, we expected an increase in the concentration of testosterone in men when: 1) axillary odors came from women with a WHR around $0.7 ; 2$ ) axillary odors came from women with the highest hormonal concentrations: estradiol (E) and progesterone (P) but not testosterone (T) because fat accumulation in the abdominal region is inhibited by estrogens, but stimulated by testosterone $[18,23,24]$. In addition, we expected that men rated as more attractive the odors of women with a WHR around 0.7 or with the highest hormonal concentration.

\section{Methods}

\section{Participants}

We recruited heterosexual undergraduate students. All the participants were paid \$15 U.S.D for their collaboration. We discarded the following samples: two males who recognized to be homosexuals, one male whose saliva sample was contaminated with blood, one male whose sample was contaminated with nicotine, one of a depressed man and one of a man because who at the end of the experiment recognized having hormonal situations. In total, there were 115 men participants (age: mean $\pm \mathrm{SD}=23.04 \pm 5.5$ ). We designed a standardized interview with women and considered them eligible if: 1) they did not take oral contraceptives or any medication 2) menstrual bleeding occurred every 28-30 days during the last six months 3 ) they had not received any hormone replacement therapy, 4) they were free of chronic or acute diseases, or any anovulatory symptoms.

Forty-five young women (age: mean $\pm \mathrm{SD}=22 \pm 2.8$ years) were carefully informed about the purpose of the study and signed a consent form. Men were told they were to participate in an olfactory perception test, in order to avoid a predisposition to search for particular scents; but upon finishing the experiment all the participants were informed what they smelled and the purpose for it. After that, no one disagreed to have their hormones measured.

\section{Collection of women body secretion, saliva samples and WHR}

The procedure of the axillary secretion collection was described in Cerda-Molina et al. [14]. We asked women to wear a sterilized cotton pad under both armpits (taped with Micropore TM tape) before they went to bed and after washing the axillary zone with a neutral soap. We instructed volunteers to wear the cotton pad without using any kind of scent (deodorant or perfume) during a whole night and to refrain from engaging in sexual activities with another person the night they had to use the pad. The following morning, the women placed the pads in sterilized plastic containers and delivered them to the laboratory (around 8.00-11.00 h). In the lab women provided a saliva sample $(6 \mathrm{ml})$, they were weighted and had their hips and waists circumferences measured. Immediately after being brought to the laboratory, the cotton pad samples were placed on a covered plastic container connected to an air pump (see below). Male volunteers, chosen at random, were instructed to participate in the test on the days when women brought samples; therefore, they smelled freshly collected material.

Women wore the cotton pads on two different days: one around mid-cycle (when steroid hormones are high) and the other around late luteal phase (when steroid hormones are low); as we did not use any vehicle to dissolve the body secretions, air was used as control situation. Based on previous research, we assumed that ovulation occurs on average 14 days prior to the onset of menstruation [25]. To minimize the variance of the cycle phase duration and of hormone concentrations, we asked all women to start the collection of samples at approximately the $12^{\text {th }}-14^{\text {th }}$ days (around ovulation) and $26^{\text {th }}-28^{\text {th }}$ days (late luteal phase) of their menstrual cycle, counting forward from the first day of menstruation. We weren't able to corroborate ovulation by means of serum hormone levels, but we obtained saliva samples every time a woman brought cotton pads to the lab. We calculated the waist-to-hip ratio (WHR) by dividing waist circumference/hip circumference in $\mathrm{cm}$ [24]. This body measurement was taken by a professional anthropologist, in order to avoid errors. Based on the mean and median value of the WHR of the 41 women (mean and median $=0.74$ ), we decided to create two categories of WHR: $0.66-0.74 \quad(n=19)$ and $0.75-0.84 \quad(n=22)$, this means that minimum-maximum WHR values were 0.66 and 0.84 .

\section{Experimental procedure}

All the experiments were performed in two clean, ambienttemperature rooms. Each male participated only once because almost all preferred not to participate again. Every woman participated more than once in different consecutive cycles, and they donated a saliva sample every time they brought axillary samples. All the experiments were done around 9:00 and 14:00 $\mathrm{h}$ in order to avoid diurnal variations of hormones. On the day a woman attended the lab to gather the cotton pad, men were contacted and asked to present to the lab; they were also instructed not to have sexual relations for $24 \mathrm{~h}$ before presenting to the experiment. After explaining the purpose of the experiment, a male experimenter took the volunteers to the experimental room. The subjects answered a general information questionnaire: age, sexual orientation and use of any medication.

We used a double-blind experimental design where participants did not know what they smelled and male experimenters (who attended male volunteers) were unaware of the odor condition being tested. Volunteers were asked to provide one saliva sample $(6 \mathrm{ml}$, pre-smell sample) at the time when they answered the questionnaire. They were then left alone to start the procedure, as all the steps were explained on the instruction sheets. We used a nebulizer air pump and a surgical face mask to deliver the odor. The body scent was placed on a covered plastic container connected to the air pump. Participants were instructed to use the mask and to turn on the pump according to the following pattern: on for 5 seconds and off for 10 seconds, 10 consecutive times. After sniffing the compounds, the subjects had to evaluate the odor according to intensity and attractiveness on a $0-6$ point scale, with 1 corresponding to not at all and 6 corresponding to very strongly. Next, volunteers had to collect the second saliva sample 30 minutes after sniffing the body odors (they were provided with a chronometer). During this time, men watched a BBC video about 
Citation: Cerda-Molina AL, Hernández-López L, Borráz-León Jl, O-Rodríguez CDL, Chavira-Ramírez R (2014) Men's Exposure to Women's Odors: The Effect of Women's Waist to Hip Ratio and Steroid Hormones. J Steroids Horm Sci 5: 141. doi:

Page 3 of 6

ocean life, a commonly used technique due to its sexually neutral content [26].

\section{Saliva hormone assays}

Immediately after finishing the experimental procedure, saliva samples were frozen using acetone and dry ice, maintained at $-70^{\circ} \mathrm{C}$ during two weeks and freed from mucopolysaccarides by three subsequent freeze-thaw cycles and centrifugation (3000 rpm x 30 min). We measured total testosterone (using chemiluminescence in the IMMULITE ${ }^{\circledR} 1000$ Siemens counter). Chemiluminescence requires the addition of 500 microliters of standards, control and samples and 1 $\mathrm{ml}$ of tracer. The lower limit of sensitivity was $0.15 \mathrm{ng} / \mathrm{dl}$. The interassay coefficient was $8.95 \%$ and the intraassay coefficient $8.02 \%$. For estradiol and progesterone, we used solid-phase Coat-A-Count 125 I radioimmunoassays (DPC, Los Angeles, CA) in duplicate, after mixing, 3 hours incubation, and decanting. We diluted the hormone standards as follows: estradiol was diluted 1:30 and progesterone 1:10 by using $4 \%$ albumin buffer at a $7.2 \mathrm{pH}$. The lower limit of sensitivity for each hormone was $0.40 \mathrm{pg} / \mathrm{ml}$ for $\mathrm{E}$ and $0.093 \mathrm{ng} / \mathrm{ml}$ for P. Interassay and intraassay values for $\mathrm{E}$ were $7.84 \%$ and $7.01 \%$, and $8.01 \%$ and $7.56 \%$ for P, respectively. The mean ( \pm s.e.m.) of hormones during the ovulatory period were: estradiol, $35.08 \pm 2.22 \mathrm{pg} / \mathrm{ml}$; progesterone, $2.157 \pm 0.11 \mathrm{ng} / \mathrm{ml}$; testosterone, $1.04 \pm 0.0170 \mathrm{ng} / \mathrm{dl}$. The mean during the late luteal ( \pm s.e.m.): estradiol, $3.903 \pm 1.61$; progesterone, $0.25 \pm 0.006$; testosterone, $0.68 \pm 0.01$.

\section{Statistics}

The analysis of testosterone concentration in men showed that the values were normally distributed (Kolmogorov-Smirnov $Z=0.364$, $\mathrm{N}=130, \mathrm{P}=0.456$ ), but scores of the odors were not (Intensity $\mathrm{Z}=1.426$, $\mathrm{N}=78, \mathrm{P}=0.034$; Attractiveness $\mathrm{Z}=2.024, \mathrm{~N}=78, \mathrm{P}=0.001$ ), hence we standardized the data by transforming rates into $\mathrm{Z}$-scores.

Female hormone concentrations were assigned to the low or the high categories based on descriptive analysis; we considered as high all concentrations up to the median value, and as low all values below the median. We performed a Generalized Estimating Equations analysis (SPSS version 17) followed by Bonferroni post hoc contrast to compare the ratings of odor perception. The subject variables were men volunteers and women the within-subject variable (repeated variable); hormone levels (high or low) and WHR categories were used as predictors. The scores of attractiveness and intensity of the odor were the dependent variables.

The changes of testosterone in men before and after smelling a female odor were analyzed using factorial repeated-measures ANOVAs. The within-subject factor was $\mathrm{T}$ concentration in men before and after smelling the female odor (variable named Time). The between-subjects factors were the stimulation sessions: control air, high or low steroid hormone sample, and WHR categories. We compared pre-smell vs. post-smell concentrations of testosterone by means of a paired sample $\mathrm{T}$ test. We included the statistical observed power. We performed a one way ANOVA analyzes to search for differences in estradiol and testosterone that depended on the waist to hip ratio categories. Finally, in order to study the correlation between WHR and hormone levels, we performed Bivariate Partial correlations controlling for the effect of the cycle phase. All data are reported as means ( \pm s.e.m.). Significance in all cases was set at $\mathrm{P} \leq 0.05$.

\section{Ethical note}

The Bioethics Committee of the Institution approved this research. We followed the Declaration of Helsinki for human research. All participants signed a consent form and were assigned a code number in order to preserve confidentiality.

\section{Results}

\section{Changes in men's T according to WHR}

The interaction time $\mathrm{x}$ WHR showed significant differences $(\mathrm{F} 1,109=3.60, \mathrm{P}=0.018$, observed power $=0.769)$. Post hoc comparisons (pre-smell vs. post-smell $\mathrm{T}$ ) indicated that neither air (control situation) nor the odors of women with WHR of 0.66-0.74 promoted changes in $\mathrm{T}$ concentration. On the contrary, $\mathrm{T}$ increased in those men who perceived odors from women with a WHR of 0.75-0.84 $(\mathrm{P}=0.034)$. These results are represented in Figure 1.

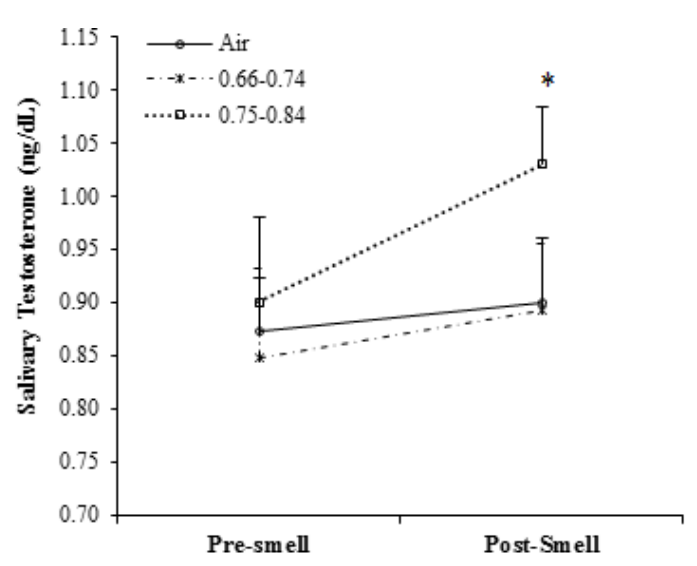

Figure 1: Mean \pm s.e.m. of salivary testosterone levels in men before (pre-smell) and after $30 \mathrm{~min}$ (post-smell) of being exposed to axillary odors from young women with different WHR categories. ${ }^{\star} \mathrm{P}=0.034$ vs. pre-smell condition. $\mathrm{T}$ increased after smelling the odor of women with $0.75-0.84 \mathrm{WHR}$.

\section{Changes in men's T according to women's hormone concentration}

Statistical analysis revealed two significant interactions: time $\mathrm{x}$ testosterone $(\mathrm{F} 2,104=5.09, \mathrm{P}=0.027$, observed power $=0.604)$ and time $\mathrm{x}$ estradiol $(\mathrm{F} 2,104=3.70, \mathrm{P}=0.03$, observed power $=0.655)$. The interaction time $\mathrm{x}$ progesterone was not significant $(\mathrm{F} 2,104=2.878$, $\mathrm{P}=0.098$, observed power $=0.380$ ). Figure 2 indicates that after exposure to high $\mathrm{T}$ women odors, $\mathrm{T}$ concentration increased in men (compared to the pre-smell concentration $\mathrm{P}=0.01$ ). Samples of low $\mathrm{T}$ women and control air did not promote changes in men's $\mathrm{T}(\mathrm{P}=0.876$ and $\mathrm{P}=0.674$, respectively). The same Figure 2 shows that after exposure to high $\mathrm{E}$ women odors, $\mathrm{T}$ concentration increased in men (compared to the pre-smell concentration $\mathrm{P}=0.008$ ). Samples of low $\mathrm{E}$ women did not promote changes in men's $\mathrm{T}(\mathrm{P}=0.2)$. 
Citation: Cerda-Molina AL, Hernández-López L, Borráz-León Jl, O-Rodríguez CDL, Chavira-Ramírez R (2014) Men's Exposure to Women's Odors: The Effect of Women's Waist to Hip Ratio and Steroid Hormones. J Steroids Horm Sci 5: 141. doi:

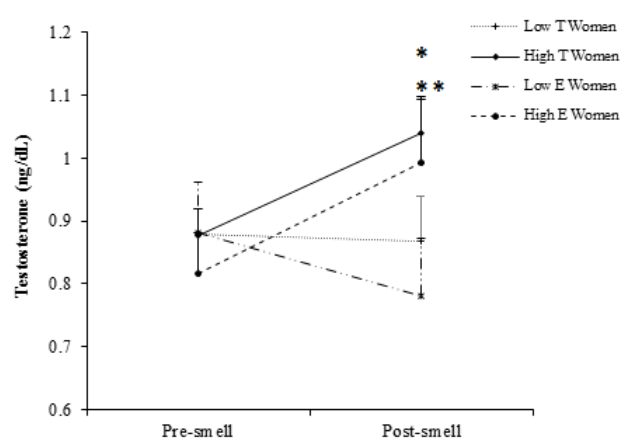

Figure 2: Mean \pm s.e.m. of salivary testosterone levels in men before (pre-smell) and after $30 \mathrm{~min}$ (post-smell) of being exposed to axillary odors from women with high or low testosterone $(\mathrm{T})$ and high or low Estradiol (E). High T women: ${ }^{*} \mathrm{P}=0.01$ vs. pre-smell condition. High $\mathrm{E}$ women: ${ }^{* *} \mathrm{P}=0.008$ vs. pre-smell condition.

\section{WHR and hormone concentrations}

We found that estradiol and testosterone were significantly different according to WHR (Estradiol: $\mathrm{F}=7.27$, d.f. $=1,80, \mathrm{P}=009$; Testosterone $\mathrm{F}=6.242$, d.f. $=1,83, \mathrm{P}=0.01$ ). Post hoc contrast indicated that both steroid hormones were highest in women in the $0.75-0.84$ WHR category compared to those in the $0.66-0.74$ category. As Figure 3 shows, testosterone and estradiol were correlated, when controlling for the effect of the cycle phase ( $T: r=0.607, n=83, P<0.001$; $E$ : $r=0.342$, $\mathrm{N}=80, \mathrm{P}=0.002$ ).

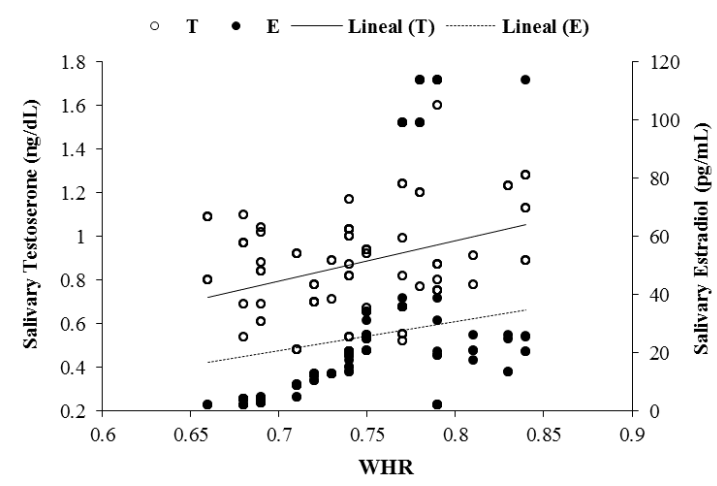

Figure 3: Salivary estradiol and testosterone of 41 women according to their WHR category

\section{Ratings of odor perception}

The reliability (Cronbach's alpha) of the odor perception ratings was 0.69 . The intensity rating did not change according to WHR (Wald Chi-square=3.112, d.f. $=1, \mathrm{P}=0.211$ ), but attractiveness did (Wald Chi-square $=5.727$, d.f. $=1, \mathrm{P}=0.05$ ). Men rated as more attractive the odors from women in the WHR category of $0.75-0.84$ compared to those in the $0.66-0.74$ category $(0.16 \pm 0.05$ vs. $-0.32 \pm 0.02)$. Men did not judge the odors as more intense according to hormonal levels (E: Wald Chi-square $=0.14$, d.f. $=1, P=0.7$; T: Wald Chi-square $=0.25$, d.f. $=1$, $\mathrm{P}=0.61$; $\mathrm{P}$ : Wald Chi-square $=0.8$, d.f. $=1, \mathrm{P}=0.9$ ). Men described as more attractive the odors of women with high levels of estradiol compared to low levels $(0.49 \pm 0.25$ vs. $-0.21 \pm 0.2)$, but not those of women with high levels of testosterone or progesterone (E: Wald Chisquare $=4.76$, d.f. $=1, P=0.029$; : Wald Chi-square $=0.15$, d.f. $=1, P=0.69$; P: Wald Chi-square $=2.1$, d.f. $=1, \mathrm{P}=0.14$ ).

\section{Discussion}

We presented evidence that axillary odors from women with different WHR and hormone levels influence men's testosterone. We found a significant increase in men's $\mathrm{T}$ after smelling the odors of women with WHR of more than 0.75 and high testosterone and estradiol concentrations. Women odors with the highest concentration of estradiol and those within the WHR category of 0.75-0.84 were rated by men as the most attractive. These findings indicate that hormone concentrations and body shape are factors that play a role in the secretion of women odors. However, these results contradict our prediction that odors from women of around 0.7 WHR would promote changes in men's testosterone, because most literature suggests that men find a female of 0.7 the most visually attractive $[2,23,27,28]$. However, most of the reports about rating of WHR have been based on modified pictures, models or play boy models, but not on real women; in fact some authors have pointed out that WHR preferences may depend on ethnic, racial, geographical and ecological parameters [29,30]. For instance, Westman and Marlowe [29] studied a population of Hadza men in Tanzania and found that men chose women with higher WHRs $(>0.8)$ as more attractive. The authors suggested that physical attractiveness elements could vary with life conditions, because women in that population do not have a real risk of obesity. Marlowe et al. [30] replicated the study of Hadza preferences but using both frontal and buttocks pictures, and they described the similar preferences (WHRs $>0.8$ as attractive). The same authors remarked the importance of geographical and ethnical variations in body shape when studying evaluations of attractiveness.

Similarly, Rozmus-Wrzesinska and Pawlowski [31] argue about the importance of WHR preferences in societies with better life conditions. The authors suggested that, in western societies, a low WHR can be valuable for a low fertility-rate population (e.g., one child), but those Latin American countries with a higher fertility rate (e.g., 6 children) and less quality of life should prefer a high WHR in order to secure reproductive success. We reported a mean WHR of 0.74 (range 0.66-0.84), a value similar to other studies of WHR in young Latin American students, 0.73 (range 0.65-0.86) [32,33] and Poland women, 0.73 (range 0.64-0.86); see Marlowe et al., [30] to appreciate a complete comparison of population data. Then, the fat deposits storage on hip and waist might be adaptive as energy reserves when the life in a harsh environment, in which nutritional constraints during pregnancy and lactation are considerable [34].

In this research, we selected those women who reported to have had regular cycles during the last six months (28-30 days) before the experiment, and discarded the women who reported irregular menstruations. It is important to note that selecting regularly cycling women forced us to reduce our sample size.

On the other hand, we found that WHR was correlated with estradiol and testosterone, regardless of the cycle phase. Although some authors have pointed out that fat accumulation in the abdominal region is inhibited by estrogens and stimulated by testosterone $[18,24]$, some other authors have described a different relationship. Kirschner et al. [35] found that the production rates of testosterone, 
Citation: Cerda-Molina AL, Hernández-López L, Borráz-León Jl, O-Rodríguez CDL, Chavira-Ramírez R (2014) Men's Exposure to Women's Odors: The Effect of Women's Waist to Hip Ratio and Steroid Hormones. J Steroids Horm Sci 5: 141. doi:

dihydrotestosterone and androstenedione in upper body obese women with WHR $>0.85$ was higher than in lower body obese women with WHR $<0.75$. In addition, the increased production of testosterone raised the aromatization of androgens to estrogens, because women with upper body obesity (WHR $>0.85$ ) had higher estradiol levels.

Our findings were similar to that described by Kirschner et al. [35] and indicated that women with WHR $>0.75$ had higher T and E salivary concentrations than women with WHR $<0.75$. The elevated hormone concentration could indirectly contribute to the synthesis of some kind of chemosignal in the apocrine glands of the armpits as we found that the rise of T in men depended on women's testosterone and estradiol levels. Some authors have suggested that specific reproductive processes could be mediated by the olfactory perception of androgens and estradiol metabolites (e.g., androstenol and estratetraenol [26,36-38]. Preti et al. [39] described cyclic variations of axillary $3 \alpha$-androstenol in women and found the highest concentrations prior to ovulation. On the other hand, Shinohara et al. [36], showed that menstrual synchrony among women, is the result of the $3 a$-androstenol capacity to regulate LH secretion after its olfactory perception. If our findings are the result of the perception of an androgen or estrogen compound, then we might assume that female odors could stimulate LH secretion in men, and consequently $\mathrm{T}$ secretion. These chemical compounds could be related to the function of signal ovulation, as we collected cotton pads on two different times, one around ovulation and the other few days before menstruation in order to have high and low hormonal concentrations. We did not analyzed cycle phase in this study, as we previously reported this effect [14]; but we performed correlation of WHR with hormones, controlling for cycle phase's effects.

In general, our results indicate that men are able to perceive axillary odors of $>0.75$ WHR women with the highest levels of $\mathrm{E}$ and $\mathrm{T}$, and in response to that odors, increase $\mathrm{T}$ concentration. We found support to the hypothesis that odors convey some information about women's physical attractiveness and endocrine condition; therefore we concluded that although humans rely mostly on vision, olfactory information plays an important role in the mate selection process.

\section{Acknowledgments}

This study was funded by a grant given to Drs Cerda- Molina AL, Hernández-López L, by “The Comisión de Estudios de Género" of the Cámara Nacional de Diputados de los Estados Unidos Mexicanos (The Mexican House of Representatives). We thank two anonymous reviewers for its corrections and suggestions to improve the manuscript. We also thank Vladimir Barberena for correcting the English.

\section{References}

1. Gangestad SW, Thornhill R, Yeo RA (1994) Facial attractiveness, developmental stability, and fluctuating asymmetry. Ethol Sociobiol 15: 73-85.

2. Singh D (1993) Body shape and women's attractiveness : The critical role of waist-to-hip ratio. Hum Nat 4: 297-321.

3. Faries MD, Bartholomew JB (2012) The role of body fat in female attractiveness. Evol Hum Behav 33: 672-681.

4. Rikowski A, Grammer K (1999) Human body odour, symmetry and attractiveness. Proc Biol Sci 266: 869-874.

5. Kuukasjärvi S, Eriksson CJP, Koskela E, Mappes T, Nissinen K, et al (2004) Attractiveness of women's body odors over the menstrual cycle: the role of oral contraceptives and receiver sex. Behav Ecol 15: 579-584.
6. Gildersleeve KA, Haselton MG, Larson CM, Pillsworth EG (2012) Body odor attractiveness as a cue of impending ovulation in women: evidence from a study using hormone-confirmed ovulation. Horm Behav 61: 157-166.

7. Preti G, Wysocki CJ, Barnhart KT, Sondheimer SJ, Leyden JJ (2003) Male axillary extracts contain pheromones that affect pulsatile secretion of luteinizing hormone and mood in women recipients. Biol Reprod 68: 2107-2113.

8. Rothardt G, Beier K (2001) Peroxisomes in the apocrine sweat glands of the human axilla and their putative role in pheromone production. Cell Mol Life Sci 58: 1344-1349.

9. Berliner DL, Jennings-White C, Lavker RM (1991) The human skin: fragrances and pheromones. J Steroid Biochem Mol Biol 39: 671-679.

10. Shinohara K, Morofushi M, Funabashi T, Mitsushima D, Kimura F (2000) Effects of 5alpha-androst-16-en-3alpha-ol on the pulsatile secretion of luteinizing hormone in human females. Chem Senses 25: 465-467.

11. Singh D, Bronstad PM (2001) Female body odour is a potential cue to ovulation. Proc Biol Sci 268: 797-801.

12. Havlícek J, Dvoráková R, Bartoš L, Flegr\$ J (2006) Non-advertized does not mean concealed: body odour changes across the human menstrual cycle. Ethology 112: 81-90.

13. Miller SL, Maner JK (2010) Scent of a woman: men's testosterone responses to olfactory ovulation cues. Psychol Sci 21: 276-283.

14. Cerda-Molina AL, Hernández-López L, De la O-Rodríguez C, ChaviraRamírez R, Mondragón-Ceballos R (2013) Changes in men's salivary testosterone and cortisol levels, and in sexual desire after smelling female axillary and vulvar scents. Front Endocrinol 4: 1-9.

15. Roney JR, Simmons ZL (2012) Men smelling women: null effects of exposure to ovulatory sweat on men's testosterone. Evol Psychol 10: 703-713.

16. Cornwell RE, Boothroyd L, Burt DM, Feinberg DR, Jones BC, et al. (2004) Concordant preferences for opposite-sex signals? Human pheromones and facial characteristics. Proc Biol Sci 271: 635-640.

17. Gangestad SW, Thornhill R (1998) Menstrual cycle variation in women's preferences for the scent of symmetrical men. Proc Biol Sci 265: 927-933.

18. Singh D (2002) Female mate value at a glance: relationship of waist-tohip ratio to health, fecundity and attractiveness. Neuro Endocrinol Lett 23 Suppl 4: 81-91.

19. Wass P, Waldenström U, Rössner S, Hellberg D (1997) An android body fat distribution in females impairs the pregnancy rate of in-vitro fertilization-embryo transfer. Hum Reprod 12: 2057-2060.

20. Deurenberg-Yap M, Yian TB, Kai CS, Deurenberg P, VAN Staveren WA (1999) Manifestation of cardiovascular risk factors at low levels of body mass index and waist-to-hip ratio in Singaporean Chinese. Asia Pac J Clin Nutr 8: 177-183.

21. Price GM, Uauy R, Breeze E, Bulpitt CJ, Fletcher AE (2006) Weight, shape, and mortality risk in older persons: elevated waist-hip ratio, not high body mass index, is associated with a greater risk of death. Am J Clin Nutr 84: 449-460.

22. Henss R (2000) Waist-to-hip ratio and female attractiveness. Evidence from photographic stimuli and methodological considerations. Pers Indiv Dif 28: 501-513.

23. Singh D (1993) Adaptive significance of female physical attractiveness: role of waist-to-hip ratio. J Pers Soc Psychol 65: 293-307.

24. Van Anders SM, Hampson E (2005) Waist-to-hip ratio is positively associated with bioavailable testosterone but negatively associated with sexual desire in healthy premenopausal women. Psychosom Med 67: 246-250.

25. Wilcox AJ, Dunson D, Baird DD (2000) The timing of the "fertile window" in the menstrual cycle: day specific estimates from a prospective study. BMJ 321: 1259-1262.

26. Bensafi M, Brown WM, Tsutsui T, Mainland JD, Johnson BN, et al. (2003) Sex-steroid derived compounds induce sex-specific effects on 
Citation: Cerda-Molina AL, Hernández-López L, Borráz-León Jl, O-Rodríguez CDL, Chavira-Ramírez R (2014) Men's Exposure to Women's Odors: The Effect of Women's Waist to Hip Ratio and Steroid Hormones. J Steroids Horm Sci 5: 141. doi:

Page 6 of 6

autonomic nervous system function in humans. Behav Neurosci 117: $1125-1134$.

27. Henss R (1995) Waist-to-hip ratio and attractiveness: replication and extension. Pers Indiv Dif 19: 479-488.

28. Streeter SA, McBurney DH (2003) Waist-hip ratio and attractiveness: New evidence and a critique of "a critical test". Evol Hum Behav 24: 8898.

29. Wetsman A, Marlowe F (1999) How universal are preferences for female waist-to-hip ratios evidence from the Hadza of Tanzania? Evol Hum Behav 20: 219-228.

30. Marlowe F, Apicella C, Reed D (2005) Men's preferences for women's profile waist-to-hip ratio in two societies. Evol Hum Behav 26: 458-468.

31. Rozmus-Wrzesinska M, Pawlowski B (2005) Men's ratings of female attractiveness are influenced more by changes in female waist size compared with changes in hip size. Biol Psychol 68: 299-308.

32. Acuña V, Gómez J, Velázquez A, Chiappa P, Ortíz V (2005) Estudio de Selección de Pareja en Población de Distrito Federal. Conaculta-INAH, México. 159-174.
33. Ramos-Ibáñez N, Ortiz-Hernández L, Ferreyra-Corona L (2011) Exactitud de las mediciones de adiposidad para identificar síndrome metabólico y sus componentes. Medicina Interna de México 27: 244-252.

34. Dixson AF (1998) Primate Sexuality. Oxford, Oxford University Press.

35. Kirschner MA, Samojlik E, Drejka M, Szmal E, Schneider G, et al. (1990) Androgen-estrogen metabolism in women with upper body versus lower body obesity. J Clin Endocrinol Metab 70: 473-479.

36. Shinohara K, Morofushi M, Funabashi T, Kimura F (2001) Axillary pheromones modulate pulsatile LH secretion in humans. Neuroreport 12: 893-895.

37. Jennings-White C (1984) Human primary odors. Perfumer and Flavorist 9: 45-58.

38. Savic I, Berglund H, Gulyas B, Roland P (2001) Smelling of odorous sex hormone-like compounds causes sex-differentiated hypothalamic activations in humans. Neuron 31: 661-668.

39. Preti G, Cutler WB, Christensen CM, Lawley H, Huggins GR, et al. (1987) Human axillary extracts: Analysis of compounds from samples which influence menstrual timing. J Chem Ecol 13: 717-731. 